\title{
POLIFONIA E INOVAÇÃO NAS PRÁTICAS EDUCATIVAS NO ENSINO SUPERIOR
}

\author{
POLYPHONY AND INNOVATION IN EDUCATIONAL PRACTICES IN HIGHER EDUCA- \\ TION \\ POLIFONÍA Y INNOVACIÓN EN LAS PRÁCTICAS EDUCATIVAS EN LA EDUCACIÓN
}

\author{
Maria Ligia Rangel Santos \\ Professora Doutora do Instituto de Saúde Coletiva da Universidade Federal da Bahia (UFBA). \\ Salvador-Bahia, Brasil. \\ lirangel@ufba.br \\ Maria Natália Pereira Ramos \\ Professora Doutora da Universidade Aberta de Lisboa (UAB). \\ Lisboa, Portugual. \\ natalia@uab.pt
}

\begin{abstract}
RESUMO: Este estudo focaliza a experiência do modelo pedagógico e-learning na Universidade Aberta de Lisboa, Portugal (UAb-Pt), mediante a análise das vozes dos sujeitos das práticas educativas. A teoria dialógica de Bakhtin direciona o estudo às vozes que compõem a polifonia: o discurso acadêmico / científico, o discurso oficial dessa universidade, e o discurso dos sujeitos da prática. A metodologia envolveu revisão da literatura, análise de documentos e realização de entrevistas semi-estruturadas com docentes e tutores. Ao nível dos resultados tentou compreender-se como os sujeitos interpretam e desenvolvem o modelo e como este se traduz em inovações, dificuldades, facilidades e desafios na prática educativa para a realização dos objetivos do projeto político pedagógico, na situação europeia atual. Ao nível das considerações finais conclui-se que o ensino na modalidade a distância tem contribuído para o sucesso educacional e para a inclusão social por meio da educação, aspecto que ganha relevância nas vozes estudadas.
\end{abstract}

PALAVRAS-CHAVE: Educação a distância. Modelo pedagógico. Modelo de educação online.

ABSTRACT: This study focuses on the experience of the pedagogical model and learning at the open university of Lisboa Portugal (UAb-Pt), through the analysis of the voices of the subjects of educational practices. The dialogical theory of Bakhtin's directs study to voices that compose the polyphony : the academic/ scientific discourse, the official discourse of that university, and the discourse of the subjects of the practice. The methodology involved reviewing the literature, analyzing documents and conducting semi=structured interviews with teachers and tutors. At the level of the results tries to understand how the subjects interpret and develop the model and how this translates into innovation, difficulties, facilities and challenges in the education practice for the accomplishment of the objectives of the pedagogical political project, in the current European situation. At level of the final considerations it is concluded that distance e learning has contributed to education success and for inclusion through education, an aspect that gains relevance in the voices studied.

KEYWORDS: Distance learning. Pedagogical model. Online education model.

RESUMEN: Este estudio se centra en la experiencia del modelo de enseñanza e-learning en la Universidad Abierta de Lisboa, Portugal (UAB-Pt), mediante el análisis de las voces de los sujetos de las prácticas educativas. La teoría dialógica de Bakhtin dirige el estudio de las voces que conforman la polifonía: el discurso académico/científico, el discurso oficial de esta universidad, y el discurso de los sujetos de la práctica. La metodología incluyó una revisión de la literatura, análisis de documentos y la realización de entrevistas semiestructuradas con profesores y tutores. En cuanto a los resultados, tratamos de entender cómo los sujetos interpretan y desarrollan el modelo y cómo esto se traduce en innovaciones, las dificultades, las comodidades y los desafíos en la práctica educativa para lograr los objetivos del proyecto político pedagógico, en la situación europea actual. En cuanto a las consideraciones finales se concluye que la enseñanza en la distancia ha contribuido al éxito de la educación y la inclusión social a través de la educación, que se convierte en un aspecto relevante en las voces estudiadas.

Artigo recebido em maio de 2017

Aprovado em julho de 2017 


\section{1| INTRODUÇÃO}

Este artigo tem por objetivo compreender a polifonia em torno das práticas pedagógicas da Universidade Aberta de Lisboa, Portugal (UAb-Pt), mediante o estudo das vozes dos docentes e tutores dessa universidade, acerca do modelo pedagógico e das escolhas tecnológicas nas atividades educativas.

A UAb-Pt é pioneira na prática de educação a distância nos países de língua portuguesa, integrando na Europa e em outros continentes, diversas instituições de ensino a distância. Seu Modelo Pedagógico Virtual, através do Programa de Inovação em Ensino a Distância, dissemina uma metodologia de ensino aprendizagem totalmente a distância.

A criação da UAb-Pt em 1988 ocorreu em um contexto de expansão do ensino superior na Europa, precedido pela Open University do Reino Unido no final da década de 1960; a espanhola UNED, criada no contexto da reforma educacional de 1970 (ARETIO, 2016); a alemã na mesma década; a holandesa e a portuguesa na década de 1980 (AMANTE, 2011), frente ao surgimento de demandas por educação, de uma classe média emergente em toda a Europa. A UAb-Pt assumiu vocação internacional, ocupando-se da promoção da cultura e da língua portuguesa dentro e fora do país e integrando a pesquisa tanto da pedagogia, quanto das tecnologias de ensino (CARMO, 1994). Contudo, propiciar um ensino de qualidade, totalmente a distância, com a introdução de metodologias de e-learning, ultrapassando barreiras física, socioculturais e temporais, não se fez sem enfrentar resistências, despertar sentimentos contraditórios, preconceitos, ignorância e desconfiança, para cumprir com o seu compromisso com a sociedade portuguesa (OLIVEIRA; MÂNTUA, 2013).

Esta Universidade realizou conquistas na educação a distância e online ao longo de quase três décadas de existência. Com abrangência transcontinental, atua na formação superior (licenciaturas, mestrados e doutoramentos), no contexto de 32 (trinta e dois) países no mundo, privilegiando também os cursos de Aprendizagem ao Longo da Vida, e integrando a sua oferta pedagógica ao Processo de Bolonha, em regime totalmente e-learning. Apostou em uma mudança radical no nível conceitual e operacional do ensino superior, particularmente do ensino a distância em Portugal (OLIVEIRA; MÂNTUA, 2013).

Em 2007 a UAb-Pt passou à 3a geração da Educação a Distância, o e-learning, abandonando radicalmente as práticas pedagógicas tradicionais do ensino a distância, que se caracterizavam principalmente pelo uso de manuais e com a tutoria presencial ou por meio telefônico. Nesse ano, tornou público o modelo pedagógico que vinha desenvolvendo e amadurecendo ao longo do tempo, através do documento "Modelo Pedagógico Virtual da Universidade Aberta - para uma Universidade do futuro", concebendo-se o modelo como "[...] um quadro geral de referência das atividades educativas e simultaneamente um instrumento organizador das práticas de ensino e de aprendizagem [...]" (PEREIRA et al., 2007, p. 8), em uma Universidade Aberta que se vê a si própria e ao seu modelo pedagógico em constante processo de construção.

O estudo da polifonia e inovação em torno das práticas pedagógicas da Universidade Aberta de Lisboa - Portugal (UAb-Pt) requer a descrição do seu modelo pedagógico e a explicitação dos fundamentos teóricos da educação a distância e do e-learning, enquanto inovação pedagógica na UAb-Pt. Inclui a análise dos discursos dos sujeitos da prática acerca do modelo pedagógico, considerando as dificuldades, facilidades e desafios que docentes e tutores enfrentam no cotidiano do trabalho pedagógico. A análise das vozes dos sujeitos envolvidos na aplicação do modelo pedagógico da UAb permite compreender como estes interpretam e desenvolvem a prática educativa cotidiana e como o modelo se traduz em dificuldades, facilidades e desafios. 


\section{2 | PERSPECTIVAS TÉORICAS DA EDUCAÇÃO A DISTÂNCIA}

Os pesquisadores da área de educação concordam que as teorias que fundamentam os modelos pedagógicos são diversas, tanto na educação presencial quanto a distância (AIRES, 2016; FERNANDES; FERREIRA, 2012). Destacam-se três grandes perspectivas como as principais na educação a distância: a associacionista, a cognitiva e a situada. A primeira, de base em teorias behavioristas, denota o ensino e a aprendizagem como resultado de mecanismos associativos/ conectivos, tendo surgido no início do século com Pavlov e Watson, com a "ênfase às mudanças observáveis do comportamento" (FILATRO, 2009, p. 96) resultantes da relação estímulo-resposta. Evoluiu no século XX com crescente complexidade, dando lugar à teoria conexionista, quando Thorndike conduz as primeiras investigações sistemáticas sobre a aprendizagem com o uso de métodos das ciências exatas, agregando a ideia de que aprender "equivale a formar, fortalecer e ajustar associações" (FILATRO, 2009, p. 97), observando mudanças de conduta, por manipulação do ambiente externo.

A instrução programada, que surgiu nas décadas de 1950 e 1960, se fundamenta nesta perspectiva e é representada principalmente por Skinner. É nesta matriz teórica que se originam os softwares educacionais. A despeito das numerosas críticas, esta é para Filatro uma perspectiva séria, frequente e erroneamente associada a um modelo de aprendizagem centrado no professor. A rigor, ela "[...] corrobora o desenvolvimento da instrução programada e de softwares que reforçam conexões através do feedback imediato [...]" (FILATRO, 2009, p. 97), enfatizando o aprender fazendo, com cuidadoso e imediato feedback dos resultados, alinhamento dos objetivos de aprendizagem com estratégias instrucionais e métodos para avaliação.

De acordo com Kop e Hill (2008), no conectivismo o conhecimento é distribuído em uma rede de informações e pode ser armazenado em diferentes formatos, porquanto entendem que aprendizagem e conhecimento se assentam na diversidade de opiniões que circulam na rede, e se traduzem através do uso das dimensões cognitivas e afetivas. Por isso, segundo estes autores, estaríamos diante do surgimento de uma nova epistemologia, embora não pareça que sua contribuição signifique uma nova teoria.

A segunda perspectiva - a cognitiva- envolve o construtivismo individual e o social. O primeiro, fundamentado em teorias genético-evolutivas, valoriza "[...] processos internos de percepção, representação, armazenamento e recuperação do conhecimento [...]" (FILATRO, 2009, p. 97), na medida em que esta não se desenvolve por uma recepção passiva do conhecimento, mas resulta da interação do sujeito com o mundo exterior, em um processo ativo de construção e reconstrução, formando estruturas cognitivas. Segundo Filatro (2009), vincula-se a esta perspectiva a aprendizagem significativa de Piaget, aprofundada por Ausubel, para quem a aquisição de conhecimentos se realiza por processos de subsunção, que permitem a agregação de novos significados a conceitos preexistentes, valorizando sobremaneira as ideias e informações já existentes na estrutura cognitiva dos aprendizes, exigindo-se organizadores prévios e o sequenciamento de conteúdos.

Também centrado no indivíduo, surge um modelo que enfatiza a memorização, e outro, com Dewey, que enfatiza a experiência de vida. Com Bruner consolida-se o construtivismo individual que reconhece que "[...]o conhecimento é um processo, não o acúmulo de sabedoria científica armazenada em textos e livros [...]" (FILATRO, 2009, p. 98). 
O socioconstrutivismo tem Vigotsky como principal autor que, em 1930, ressaltou as raízes sociais da aprendizagem significativa, reconhecendo que "[...] as funções psicológicas são fruto do desenvolvimento cultural e não do desenvolvimento biológico [...]” (FILATRO, 2009, p. 97). Para Jonassen, "Se o significado é pessoal, não é necessariamente individual [...]", pois "[...] pode ser ajustado socialmente entre grupos de pessoas [...]", de modo que compartilhamos não só o mundo físico mas também a percepção dele. Assim, o aprendizado, da perspectiva construtivista, "[...] é diálogo - interações consigo mesmo ou com outros" (JONASSEN, 1996, p. 71).

A terceira perspectiva, a situada, enfatiza o contexto social da aprendizagem e a ação das pessoas e grupos, como fontes privilegiadas do conhecimento, o qual é distribuído socialmente. Muitos autores se referem à cognição situada relacionada a noções como autenticidade, aprendizagem baseada em problemas, instrução ancorada, dentre outros (HUNG; LOOI; KOH, 2004). Nesta perspectiva, aprender "[...] envolve interagir com outras pessoas, ferramentas e o mundo físico [...]" (FILATRO, 2009, p. 98), em um contexto histórico e cultural próprio. A interação social e a colaboração são componentes críticos para a aprendizagem. O estudante é estimulado a dialogar com os outros, a compartilhar e assumir posturas de escuta e valorização do outro, inseridos em campos de práticas em ambientes realistas e informais onde participam, tornando a aprendizagem autêntica e gerando um sentido de pertencimento a uma comunidade.

As perspectivas apresentadas acima possuem implicações diferentes para a aprendizagem, o ensino e a avaliação. Assume tarefas mais formalmente estruturadas na perspectiva conexionista, e em contextos de aprendizagem mais autênticos, na situada. Contudo, o uso diversificado de métodos permite vislumbrar pontos de intersecção entre as diferentes perspectivas, os diversos conhecimentos historicamente acumulados e as distintas tecnologias educacionais utilizadas.

\section{3| E-LEARNING: UMA INOVAÇÃO PEDAGÓGICA}

O Eletronic-learning (e-learning) é considerado uma modalidade educativa inovadora (VELASQUEZ; LOPEZ, 2009; GARCÍA; ESTEBAN, 2009; MASON, 2003), caracterizada pelo uso do meio eletrônico e totalmente a distância. Desenvolve-se "[...] através da criação de ambientes virtuais flexíveis, abertos e interativos; dispondo de todos os materiais necessários para a aprendizagem do estudante [...]" (VELASQUEZ; LOPEZ, 2009, p. 5) e que integra a comunicação interativa através de um conjunto de recursos tais como: fóruns, chat, videoconferências, multimídia, vídeos, apresentações e outros documentos que guiam o desenvolvimento cognitivo. Esta modalidade educativa é socialmente inclusiva, pois o estudante pode estar em qualquer parte do mundo, necessitando apenas ter acesso e habilidade de manejo de um computador.

Alguns autores afirmam que a educação a distância tem se convertido em elemento chave para a inovação de práticas pedagógicas, por oferecer numerosas possibilidades de uso da tecnologia, apoiada em diversas perspectivas teóricas (FILATRO, 2009; TELES, 2009), principalmente na educação superior, com as virtudes da flexibilidade, acessibilidade, centralidade no aluno, dentre outras. Contudo, deve-se atentar para que esta seja também sinônimo de exigência de qualidade, haja vista que a flexibilidade, a personalização, a autonomia, a interatividade e a cooperação devem ser colocadas a serviço dos estudantes, em todos os tipos de modelos educativos, sejam eles convencionais ou os que se dão em contextos de ambiente virtuais de aprendizagem (MORER, 2003).

Segundo Avendaño (2013), modelos pedagógicos são construções provisórias, não absolutas nem determinadas, podendo variar e desaparecer de acordo com o avanço científico e também conforme as teorias, concepções e princípios que os fundamentam. Assim, um modelo pedagógico é formado com aportes teóricos adotados conforme as necessidades dos sujeitos de aprendizagem, 
e são modificáveis de acordo com os fins que se deseja alcançar, em contextos em que os estudantes habitam e aprendem. Decorrem das relações entre os atores pedagógicos, e são sempre alternativos e complementares, nunca universais. Portanto, conclui-se que são numerosos os modelos pedagógicos e suas categorizações.

Embora crescente a experimentação com distintos pontos de vista, para atender à gama de aprendizagem com diferentes estilos, diferentes pontos de partida do ensino ou diversos contextos dos alunos, a tecnologia mediada facilita, mais que o ensino face-a-face, a possibilidade de personalizar o ambiente virtual de aprendizagem. Assim situam-se os estudos voltados para estilos e itinerários de aprendizagem, como os de Bechara e Haguenauer (2012a, 2012b).

De todo modo, a Educação a Distância é um campo de inovação, não só quanto aos ambientes, mas também quanto aos modelos de aprendizagem. Os primeiros podem ser variados, desde sistemas multimídia, hipermídia, objetos de aprendizagem, games, realidade virtual (SOBRINHO; HAGUENAUER, 2012); os segundos incluem a experimentação e incorporação de diversas estratégias pedagógicas, tais como a aprendizagem significativa, aprendizagem colaborativa, lúdica, dentre outras. Diversos aspectos caracterizam o e-leaning: o tipo de comunicação entre professor-aluno e aluno-aluno; o papel do professor e do tutor, do aluno, o tipo de mediação da aprendizagem; os modos de interação, os modos de avaliação; a gestão do tempo; a escolha das ferramentas, se síncronas ou assíncronas.

Algumas inovações se destacam, no campo da educação a distância, e têm chamado a atenção de muitos pesquisadores e professores voltados para as necessidades educacionais das sociedades multiculturais, plurais, globais, digitais e em rede, mais do que para o desenvolvimento industrial da educação (CASTELLS, 2002; GIDDENS, 2002; RAMOS, 2016).

Diversos autores reconhecem o potencial emancipador em processos educacionais de educação a distância, especialmente com o advento da web 2.0. Fontes, Scareli e Versuti (2011) destacam que na aprendizagem significativa, de perspectiva construtivista, "[...] as tecnologias de informação e comunicação devem ser usadas como ferramentas de aprendizagem e não como veículos de transmissão de mensagens [...]" (FONTES; SCARELI; VERSUTI, 2011, p. 126), pois trata-se de construir o conhecimento e não de transmiti-lo. A construção do conhecimento processa-se a partir "[...] do engajamento do aprendiz em uma atividade [...]" (FONTES; SCARELI; VERSUTI, 2011, p. 126), enquanto o processo de significação, inerente à aprendizagem, deve estar ancorando no contexto, requerendo articulação, expressão e representação do que é aprendido.

Centrar a educação no aluno e não no professor, é um importante posicionamento pedagógico que favorece a uma educação emancipadora (GOMEZ, 2004), considerando-se que, mais importante do que o ensino é a aprendizagem. Busca-se estratégias que permitam respeitar as características de cada aprendiz, propiciar espaços de interação e diálogo, mediante a comunicação não só entre alunos e professores, mas também entre alunos-alunos e todos com todos (ALVES; NOVA, 2003).

Ademais, adverte-se sobre a importância de desenvolver a autonomia do aprendiz, isto é, a capacidade de gerir sua própria aprendizagem, pois, apenas o fato de lidar com tempo e espaço flexíveis não é condição suficiente para que o estudante se torne autônomo. Com efeito, o aluno precisa aprender a gerir o tempo e organizar os estudos, motivo pelo qual a atividade interativa revela-se como o meio fundamental para que esta autonomia se desenvolva, pois "[...] pensar em autonomia do aluno implica em aliar autonomia com diálogo [...]", pois somente através do diálogo, da comunicação, "[...] o aluno é provocado para a crítica, para a autonomia intelectual [...]" (ROMÃO; MATTOS, 2011, p. 65). Não se deve, portanto, confundir autonomia com autodidatismo, auto estudo com trabalho individual.

A inclusão digital tem sido ressaltada na literatura como uma forma expressiva da inclusão social na sociedade contemporânea (GADOTTI; ROMÃO, 2004). Para esses autores, "[...] a ideia de 
rede é, talvez, a mais notável noção de educação contemporânea [...]" (GADOTTI; ROMÃO, 2004, p. 15) pelo seu potencial de expansão do acesso ao conhecimento e à informação.

Além da internet, destaca-se o uso dos dispositivos móveis na educação. As sociedades no mundo globalizado, em constante movimento e mediação tecnológica, tornam o contato e convivência entre os povos e culturas uma marca nunca vista em outros tempos da história de humanidade. Ademais, aprender é ao mesmo tempo necessidade e consequência desse modo de estar no mundo. Assim, o uso dos dispositivos móveis em educação é uma realidade, representando também uma inovação pedagógica importante no processo de inclusão social, digital e intercultural (SANTOS; RAMOS, 2016). A Unesco afirma que se acentua o crescimento de evidências sugestivas de que os dispositivos móveis estão disseminados por toda parte do mundo, principalmente telefones celulares e tablets, e utilizados cada vez mais por "[...] alunos e educadores de todo o mundo para acessar as informações, agilizar a administração e facilitar a aprendizagem de maneiras novas e inovadoras [...]" (UNESCO, 2013, p. 6).

\section{4 | TEORIA E MÉTODO}

Este estudo fundamenta-se na teoria do dialogismo de Bakhtin, focalizando as vozes dos docentes e tutores sobre os modelos pedagógico dessa Universidade, especialmente voltados para o modelo atual de Educação a Distância de terceira geração, o e-learning. O estudo abarca a leitura do discurso oficial da UAb-Pt sobre o modelo pedagógico com seus princípios, recursos, ferramentas e inovações, e das vozes de docentes e tutores que cotidianamente interpretam o modelo e desenvolvem as práticas de ensino-aprendizagem.

Com base na teoria do dialogismo de Bakhtin (1981), entende-se a pedagogia como uma prática discursiva e polifônica, própria de qualquer ação social, e que tem inspirado vários trabalhos de leitura de atividades educativas e do discurso acadêmico (DIAS, 2014; FLORES; SILVEIRA, 2012; CHAGURI, 2010; FREITAS, 2011; AIRES, 2003), devido à riqueza que este referencial oferece para compreender um fenômeno vivo, interativo e dinâmico, como são a prática pedagógica e da produção científica.

Bakhtin desenvolve o conceito de polifonia sobre o texto literário clássico de Dostoievsky, que para ele tem caráter dialógico, aberto e polifônico como a vida social. Para o autor, "[...] a essência da polifonia consiste justamente no fato de que as vozes permanecem independentes [da voz do autor] e, como tais, combinam-se numa unidade de ordem superior à da homofonia, sem a subordinação teleológica [...]" (BAKHTIN apud ROMAN, 1992, p. 211). Polifonia em que, tudo no mundo do texto "[...] vive na fronteira com o seu contrário." (BAKHTIN apud ROMAN, 1992, p. 212). A polifonia desse modo diz respeito à multiplicidade de vozes, às diferenças, às subjetividades, às ambiguidades de sujeitos vivos em interação.

A linguagem em Bakhtin é concebida como um produto social, coletivo e histórico, que se desenvolve na interação comunicativa e é recriada "a cada momento pelos falantes" e em constante mutação (ROMAN, 1992, p. 217). Assim, Bakhtin dá lugar ao plurilinguismo, ao multi/interculturalismo, à independência das vozes no texto, o que permite ao pesquisador aproximar-se das diferenças e da riqueza de representações existentes na realidade social.

Nessa pesquisa, procura-se a leitura e a escuta de algumas das muitas vozes que compõem a polifonia da prática pedagógica na UAb-Pt: dos pesquisadores, docentes e tutores da instituição. Não se trata de contrastar as vozes, mas de ouvi-las e compreendê-las, a partir do trabalho interpretativo.

Trata-se de um estudo de caso, de natureza qualitativa, orientado para a experiência de e-lear-ning da UAb-Pt, com vistas a analisar seu modelo pedagógico a partir das vozes de docentes e tutores 
dessa universidade. A metodologia do estudo consistiu no estudo de documentos oficiais que delineiam o modelo pedagógico UAb-Pt e na realização de entrevistas semiestruturadas, gravadas e transcritas, com cinco informantes-chave, sujeitos da prática, em posição representativa, segundo critério de maior experiência na UAb-Pt, sendo três docentes pesquisadores - um deles participante da gestão inicial da UAb-Pt -, e dois tutores pesquisadores - dois atuantes no $10 \mathrm{e}$ 20 ciclos (Miguel e Luiza); um atuante apenas no $1^{\circ}$ ciclo (João) -; e duas tutoras atuantes no 10 ciclo (Maria e Regina), cujos nomes são fictícios. As entrevistas foram concedidas mediante assinatura de Termo de Consentimento Livre e Esclarecido, realizadas na UAb-Pt e orientadas por um roteiro que abordou as seguintes categorias para a análise: a experiência em $E A D$, dentro e fora da UAb; formação docente para atuar em EAD; visão do modelo pedagógico; facilidades e dificuldades encontradas na sua operacionalização, enfocando o ensino, a aprendizagem, a avaliação; sugestões de modificação do modelo; aproximação e distanciamento do modelo proposto à prática cotidiana; facilidades e dificuldades; principais desafios da prática para o alcance dos objetivos do projeto político pedagógico dessa Universidade.

\section{5| UNIVERSIDADE ABERTA DE LISBOA, PORTUGAL E SEU MODELO PEDAGÓGICO A DISTÂNCIA E ONLINE}

Em 2007, o modelo pedagógico da UAb-Pt, segundo Amante (2011), transita de um modelo "[...] centrado na distribuição ao estudante de um pacote de materiais de aprendizagem", para um modelo "centrado no desenvolvimento de competências com recurso integral aos novos instrumentos de informação e comunicação proporcionados pela Web" (AMANTE, 2011, p. 3). Este modelo se fundamenta na perspectiva interacionista individual e social, valorizando a dimensão do contexto, com centralidade no aluno, na aprendizagem interativa, participativa e colaborativa, que são elementos diferenciais para o pleno desenvolvimento de competências necessário à educação, no nível do saber, saber-fazer e saber ser, realizando um trabalho pedagógico para além da mera recepção de conteúdo.

Trata-se de um modelo que responde ao desenvolvimento tecnológico via web, criando novos contextos e modalidades de aprendizagem e reconfigurando o suporte tecnológico para promover novas formas de interação e comunicação multidirecional entre estudantes-estudantes e professor-estudante.

Assim a UAb-Pt define que novos modos de ensinar e aprender devem ser combinados com posturas pedagógicas que comprometam e responsabilizem o estudante como sujeito ativo e participativo no seu processo de aprendizagem, com vistas ao pleno desenvolvimento metacognitivo e a adoção de atitudes construtivas, colaborativas e autônomas, em consonância com o discurso acadêmico de perspectiva inclusiva e emancipadora. A aprendizagem colaborativa ocorre por meio da formação de turmas virtuais, comunidades de aprendizagem que compartilham saberes e competências por meio de interações colaborativas.

Trata-se pois de contextos de aprendizagem que se inscrevem nas perspectivas sócio-construtivistas em que a aprendizagem se centra no aluno e não no professor e onde assume particular relevância a interacção entre pares e o contexto em que a aprendizagem ocorre. (AMANTE et al., 2008, p. 8).

Ademais, o modelo pedagógico virtual da UAb está "[...] assente num conjunto de princípios pedagógicos fundadores e consubstanciados em variantes didáticas específicas de acordo com a diversidade de cursos existentes [...]" (PEREIRA et al., 2007, p. 9). São princípios fundamentais que 
devem funcionar como "linhas de força": a aprendizagem centrada no estudante; a flexibilidade; a interação e inclusão social. Estas devem nortear a organização do ensino, o papel do estudante e do professor, a planificação, concepção e gestão de atividades de aprendizagem, os tipos de materiais e a avaliação.

Com tais pressupostos delineia-se um percurso de aprendizagem que deve conduzir ao desenvolvimento de competências transversais (de vida em sociedade) e competências específicas da área de saber escolhida. O planejamento então deve ser realizado de forma rigorosa em cada unidade curricular, em função dos objetivos e das competências que se espera desenvolver.

A aprendizagem tanto pode se desenvolver de forma independente, ou "[...] através do diálogo e da interação entre pares, com base em estratégias de aprendizagem cooperativa e colaborativa" (PEREIRA et al., 2007, p. 10), o que pressupõe a criação e organização de grupos, no sentido da construção social e contextualizada, e da ruptura com o isolamento e desmotivação do estudante, além de prepará-lo para atuar nas organizações modernas cujas tarefas são interdependentes. Espera-se do estudante um papel ativo na gestão de suas atividades, atuando de forma autônoma e criativa no seu processo de aprendizagem.

Ao adotar a pedagogia online, cabe ao professor facilitar e colaborar na comunidade de aprendizagem, com postura permanentemente reflexiva e investigativa sobre a prática, ao mesmo tempo rigoroso e atento às necessidades do estudante. São suas competências: gestão do conhecimento; trabalho em equipe; disponibilização de recursos diversificados; e organização de atividades enriquecedoras que promovam a reflexão e colaboração entre os estudantes.

Nesse modelo, o rigor do planejamento convive com a flexibilidade. Esta significa que o estudante pode aprender no seu tempo e lugar, mediante a participação prioritária em fóruns de discussão e outros modos assíncronos da Web 2.0. Os programas são preferencialmente semestrais, em todas as unidades curriculares, para aumentar a flexibilidade.

O princípio da interação estudante-estudante, professor-estudante, é contemplado pela estratégia de criação de grupos de discussão em cada turma virtual, no qual o professor tem presença fundamental e indispensável.

Compreendendo que info-exclusão significa exclusão social e marginalidade, a UAb adota o princípio da inclusão digital "[...] entendido como a facilitação do acesso aos adultos que pretendam frequentar um programa numa instituição superior e não tenham habilidades com o uso das Tecnologias de Informação e Comunicação" (PEREIRA et al., 2007, p. 14). Este desafio aos sistemas educacionais, frente ao crescente desenvolvimento tecnológico, leva a UAb-Pt a assumir como objetivo educacional central "[...] a promoção de estratégias educativas que contribuam para a aquisição e desenvolvimento de literacia digital dos estudantes [...]", mediante a criação de "[...] uma rede de pontos de acesso virtual, através do desenvolvimento de sinergias com parceiros locais [...]" (PEREIRA et al., 2007, p. 15), com sistema de helpdesk permanente. Ademais, todos os programas de formação certificados devem oferecer um "[...] módulo prévio, de frequência gratuita, para que os novos estudantes possam adquirir essas competências [...]" (PEREIRA et al., 2007, p. 15), de modo que frequentar a Universidade Aberta se torne uma experiência de inclusão digital.

A UAb-Pt apresenta três vertentes de seu modelo pedagógico: "1- uma variante, inteiramente virtual, destinado aos cursos do 10 ciclo; 2 - uma variante dedicada a cursos do 20 ciclo, com duas modalidades: classe virtual e classe mista; 3 - uma variante para cursos de curta duração" (PEREIRA et al., 2007, p. 9).

Distinguem-se os elementos pedagógicos dos 10 ciclo e 20 ciclo, destacando-se no primeiro as classes virtuais com o máximo de 50 alunos, na $1^{a}$ fase, com atribuições bem definidas para os sujeitos envolvidos, e com "caráter mais didático", podendo o currículo ser colaborativo e construtivista, em uma $2^{a}$ fase, ou se a turma tiver um número menor de estudantes. 
As classes virtuais possuem "[...] o recurso de sistemas informáticos que permitem a interacção, a distribuição da informação e a gestão dos espaços de aprendizagem" (PEREIRA et al., 2007, p. 20). O professor como ator fundamental monitora as atividades dos estudantes, que devem se responsabilizar pela sua aprendizagem. Os grupos de estudantes são organizados em fóruns e devem funcionar como comunidades de aprendizagem autônomas, com o estímulo do professor. Quando moderados pelos próprios estudantes, caracterizam-se como espaços de interação próprio dos alunos. Os fóruns moderados pelo professor, por sua vez, devem discutir questões já trabalhadas pelos estudantes em seus espaços interativos de trabalho. Ademais, a comunicação síncrona entre os estudantes poderá propiciar a socialização e o desenvolvimento de comunidades virtuais de aprendizagem, embora o modelo privilegie a comunicação assíncrona. A gestão do curso é realizada por um coordenador que organiza todo o processo de planejamento e acompanha o seu desenvolvimento.

Superadas a $1^{\text {a }}$ geração da EAD (fase dos manuais) e a $2^{\mathrm{a}}$ geração (fase da interação do aluno com os conteúdos), os recursos pedagógicos são, no modelo e-learning, os mais variados, advogando-se a produção de obras de referência como o uso de matérias disponíveis livremente na Web e diversos objetos de aprendizagem, considerando o desenvolvimento da Web 2.0 e incluindo os dispositivos móveis, pertinentes à $3^{\mathrm{a}}$ e $4^{\mathrm{a}}$ geração da EAD.

As duas modalidades de classe do 20 ciclo, a virtual e a mista, são aplicáveis também ao 30 ciclo. Considerando que o 20 ciclo ocorre em nível de pós-graduação, o trabalho dos estudantes deve ser inovador e com grande autonomia. O número máximo de estudantes por turma/professor é entre 20 e 25, no 20 ciclo, enquanto o 30 ciclo opera com turmas menores, de 10 a 15 estudantes. A investigação exigida nesses ciclos requer a orientação personalizada. Todas as atividades são realizadas online, integrando os diversos recursos disponíveis na web 2.0, especialmente blogs, wikis, e-portefólios, agregador de notícias e outros.

Nas classes mistas, a interação face-a-face tem caráter secundário, com apenas $25 \%$ das horas de contato, objetivando principalmente a socialização, a apresentação de professores e estudantes, apresentação de trabalhos finais, dentre outros.

Obriga-se neste ciclo a avaliação contínua, que pode ser complementada com trabalho final, enquanto o sistema de coordenação é mais centralizado do que no 10 ciclo, visando um acompanhamento mais personalizado do estudante.

A Aprendizagem ao Longo da Vida consiste em programas educativos diversificados, seja na forma de cursos rápidos certificados, para formação de competências específicas ou fruição cultural, inteiramente virtuais ou com momentos presenciais.

Ressalta-se, dentre os aspectos inovadores desse modelo pedagógico, a aprendizagem em movimento, com uso dos dispositivos móveis, e o contrato de aprendizagem. A aprendizagem em movimento (mobile learning, ou m-learnnig) foi motivada na UAb-Pt pela Declaração de Bolonha em 1999, que estabeleceu conceitos e parâmetros para facilitar a integração e internacionalização nos aspectos educacionais na Comunidade Europeia, trazendo o desafio de incorporar a interculturalidade e a mobilidade como princípios e estratégias educativas (SOBRAL; RAMOS, 2012, 2015). Destaca-se entre as estratégias pedagógicas e ferramentas educacionais e comunicacionais mais atuais, pela sua importância num mundo globalizado com o aumento dos diversificados fluxos de mobilidade, devido aos intensos movimentos migratórios. Alia-se a esta característica o crescente acesso às tecnologias móveis.

O Contrato de Aprendizagem é uma inovação que propicia, desde o primeiro contato do estudante com o professor, a sua participação na definição do plano de estudos que irá desenvolver ao longo de um curso. Trata-se de um documento submetido à apreciação do estudante no início do curso, o que implica, desde o início, no seu protagonismo, conferindo-lhe poder de decisão sobre 
o seu processo de ensino-aprendizagem. Deste modo, o professor apresenta uma proposta, o plano de trabalho, que pode ser modificado conforme a apreciação dos estudantes que, nesse momento, realizam um contrato com o professor sobre o que ocorrerá ao longo do curso. Esse contrato propicia que se estabeleça a relação professor e estudante no contexto grupal, em cada unidade curricular, funcionando como um "mapa de navegação" para ambos, ao longo do percurso da aprendizagem, permitindo que o estudante, logo no início da unidade curricular se organize e defina prioridades.

O sucesso e os desafios do modelo pedagógico da UAb são bem discutidos por Mansos (2014), por Oliveira e Mântua (2013) e por Amante (2011), especialmente no que se refere à formação docente. Também Sobral e Ramos (2013) destacam em pesquisa sobre narrativas de docentes acerca do modelo pedagógico da UAb, o caráter inovador e intercultural, reconhecido pelos pesquisados, e a riqueza do modelo, que promove mudanças significativas em suas práticas pedagógicas. No entanto, no campo da investigação, ainda são poucos os estudos que elegem as práticas pedagógicas desta universidade como objetos de estudo.

\section{6 | DIALOGISMO NAS VOZES DOS SUJEITOS DA PRÁTICA}

As vozes dos entrevistados permitem a aproximação às formas como o modelo é interpretado na prática dos docentes e à sua instanciação, ou seja, os modos como os contextos reais incidem sobre as inovações, produzem mudanças e podem ser traduzidos em novos conceitos.

As vozes dos entrevistados convergem para afirmar que o modelo pedagógico da UAb-Pt na prática funciona bem, sem deixar de evidenciar suas contradições. Embora as condições de sua aplicação tenham se modificado significativamente ao longo dos anos, em geral, os discursos enfatizam os aspectos da estruturação e organização do modelo que, se antes propiciavam segurança e conforto a quem realizava as práticas educativas, atualmente, ao contrário, resultam em rigidez que impede a criatividade. Entretanto, as distintas formas de interpretação do modelo decorrem do tempo e lugar de inserção dos sujeitos na universidade. Alguns entrevistados estavam desde o início da criação da UAb-Pt e experimentaram o modelo tradicional e a formação imersiva oferecida na transição para o modelo e-learning. Outros entrevistados chegaram quando já não se disponibilizava tal formação, transitando diretamente da experiência presencial em outras universidades para o e-learning na UAb-Pt.

Embora a vozes dos entrevistados evidenciem que o modelo pedagógico da UAb-Pt não se distingue muito dos modelos de outras universidades em que trabalham (Regina; João; Maria), a forma de organização do primeiro ciclo e os demais (segundo e terceiro) é identificada como sua particularidade. Enfatiza-se o aspecto da organização, que permite ao estudante saber, desde o início, com se processarão as atividades (Regina), mediante a discussão e assinatura do contrato de aprendizagem, e poder decidir junto com o professor o seu plano de estudo.

Contudo, ressalta-se que o modelo e-learning da UAb-Pt, embora adepto da flexibilidade quanto a tempo e lugar de desenvolvimento das atividades, possui regras bem definidas, consideradas até mesmo rígidas, por uma necessidade de ganhar credibilidade no momento em que ela foi criada, o que funcionava como uma estratégia tanto para a uniformização das atividades, frente à necessidade de propiciar conforto e segurança, para os docentes atuarem em um ambiente desconhecido, e também reduzir as resistências (João).

Apesar de as vozes serem uníssonas ao apontar distorções no modelo dadas pelas condições de operacionalização nos últimos cinco anos, os discursos sugerem que as práticas docentes mudaram radicalmente com a implantação do e-learning, o que foi enunciado especialmente por aqueles que trabalharam com o modelo tradicional (Miguel; Luiza). 
Foram apontadas mudanças significativas na relação professor-aluno, pois com o e-learning percebe-se maior contato entre eles, se comparado com o modelo de ensino anterior, no qual ocorria grande isolamento dos estudantes, quando a interação era, sobretudo, com os conteúdos recebidos em materiais impressos ou multimídia (Luiza).

Quando se trata do 20 ciclo, essa relação torna-se ainda mais intensa para desenvolver atividades que produzam evidências (Miguel). São utilizadas várias técnicas para o desenvolvimento de competências variadas, individuais e coletivas, para a reflexão, a produção de texto, a capacidade de análise, mediante fóruns em que o professor orienta as atividades, coloca os temas, organiza a discussão. Os fóruns podem ser também orientados pelos próprios estudantes, na perspectiva da aprendizagem colaborativa e em rede, com objetivos definidos pelo professor, cabendo ao estudante se organizar, escolher os papéis a desempenhar, distribuir tarefas, entre outros (Miguel).

O acompanhamento dessas atividades modifica a relação, uma vez que o professor, embora não esteja lá no ambiente virtual de aprendizagem (AVA) 24 horas, nem os encontre pontualmente em sala de aula, está regularmente gerindo a interação, num dado período de tempo, imprimindo uma dinâmica temporal ao grupo de estudantes, o que intensifica e reconstrói a relação (Miguel). A gestão do tempo se faz ao responder prontamente às dúvidas e questões, ou demorando-se a fazê-lo, tornando vigorosa a interação, provocando o grupo para que os estudantes se comuniquem ou busquem as respostas com autonomia (Miguel), tornando a aprendizagem interativa e participativa uma realidade no ambiente virtual.

O discurso do/a docente que não trabalhou na UAb na fase de $1^{a}$ geração de EAD se diferencia daquele que não só trabalhou desde a criação da UAb, mas também foi um dos criadores do modelo, evidenciando vozes contraditórias. No primeiro caso, o enunciado é o de que o atual modelo distancia docentes e estudantes, no nível físico e emocional (Regina). No segundo caso, o modelo atual aumenta a intensidade da relação professor-aluno, aliada à mudança do tempo psicológico, dado pela interação assíncrona, em que se promove a comunicação escrita, a qual permite maior tempo na construção da resposta, e "[...] também aumenta a perenidade, a pregnância da própria comunicação [...]. Você vê que está ali algo que precisa ser respondido. E isso cria uma pressão psicológica" (Miguel). Nesse discurso, o tempo é prolongado, diferente do tempo de uma sala de aula presencial, que é limitado, e isso promove uma "[...] pressão é muito grande para responder, para interagir, e isso cria uma dinâmica" (Miguel). Nesse sentido, evidencia-se uma interação que se dá para além da estabilidade do mundo físico ou biológico, como possibilidade de desenvolvimento imprevisível e indefinidamente aberto (SILVA, 2002, p. 93).

As vozes convergem na compreensão do e-learning como um modelo nem mais fácil, nem mais simples, que o ensino presencial. Para Miguel, ao contrário do que se pensa, alguns aspectos podem ser mais difíceis de gerir, pois "[...] é uma comunicação mais dura, mais pura. Mas também por isso mesmo, os próprios códigos da comunicação e a força das palavras é maior". A intensidade das palavras, tanto positiva quanto negativa, tornaria mais complexa a gestão de conflitos entre os atores da comunidade on line, "[...] porque não há essas outras formas complementares a construir o ato de comunicação" (Miguel), ou seja, trata-se de uma comunicação em que o gestual, a entonação, e outros marcadores linguísticos não estão presentes na construção do sentido.

A possibilidade de realizar práticas educativas a pessoas que, de outro modo, não teriam a oportunidade de estudar, surge como um forte motivador dos entrevistados. Vozes uníssonas sugerem que talvez seja o aspecto da inclusão social o que mais os motiva a se envolverem com o modelo pedagógico a distância. O modelo se configura como uma vantagem para determinado tipo de pessoas "[...] em situação de isolamento, [...] numa situação de algum modo vulnerável por algum aspecto [...], e percebermos que, para algumas pessoas, é a única possibilidade de elas 
realizarem o seu sonho de continuarem a estudar" (João). Esse aspecto faz os entrevistados se sentirem bem, por estarem contribuindo com essas pessoas (João; Maria; Regina).

Aliado a isso, destacam-se as facilidades de realização do trabalho, tanto do aluno como do docente em qualquer tempo e lugar (Maria), o que assegura a "liberdade de ir para qualquer sitio e poder estar sempre a acompanhar os alunos. Podemos ir para Congressos, podemos ir para qualquer situação e é só abrir o computador [...]" (Regina). O mesmo ocorre com o aluno que "[...] pode estar em casa, no trabalho, em qualquer sítio, acho que é das melhores facilidades que o e-learning pode ter" (Regina). Esta tem sido talvez a principal característica e benefício da educação a distância já destacada amplamente na literatura.

Um ponto forte do modelo, que Ihe é característico e também um desafio para os docentes, é estruturar as atividades de forma participativa, interativa e propiciar a aprendizagem colaborativa, da perspectiva construtivista social e individual, de modo que os alunos, situados em diferentes contextos, entrem em contato, troquem ideias e construam o conhecimento de um modo coletivo, mesmo estando a distância e sem se conhecerem. Nesse sentido, as vozes revelam consonância com a literatura (CASTRO; MATTEI, 2008) sobre o papel de mediador da aprendizagem que cabe ao professor, o qual é fundamental para lidar com as dúvidas, as questões, remetendo-as ao grupo e estimulando a contextualização e participação de todos na busca e construção do conhecimento. Essa atividade é especialmente difícil com o aumento do número de estudantes por turma, que ocorreu nos últimos cinco anos. Para enfrentar os desafios, confluem vozes que sugerem obedecer ao previsto no modelo.

O principal aspecto que incide negativamente sobre o modelo, modificando-o no contexto real, diz respeito ao excesso de carga horária docente, que ocorre devido ao aumento do número de estudantes por turma, acima do preconizado, comprometendo a qualidade da interação e da aprendizagem. São também destacados aspectos psicológicos, a exemplo da pressão psicológica sobre os docentes, devido aos prazos para cumprimento das tarefas e ao excesso de estudantes; e a ansiedade deslocada nos estudantes, frente à espera por resposta para uma dúvida.

No diálogo entre as vozes, destoam aquelas dos que estão no lugar de tutor, para quem a estrutura e organização do modelo, embora por um lado seja um conforto, são consideradas excessivas, surgindo como fator limitante da liberdade e criatividade, uma vez que ao tutor cabe apenas operacionalizar o que o docente define, mesmo que seja um profissional qualificado em nível de mestrado ou doutorado. Contudo, é este quem realiza a mediação entre os conhecimentos tácitos dos aprendizes e os conhecimentos teóricos que o professor pretende compartilhar na construção coletiva e significativa de novos conhecimentos (CASTRO; MATTEI, 2008).

Não obstante, em virtude de tudo já se encontrar organizado: conteúdo, ferramentas e tempo programado, insatisfações têm sido verificadas entre esses profissionais, porquanto não lhes é permitido respeitar o tempo do aluno, na medida em que, mesmo avaliando que determinado período foi insuficiente para que a aprendizagem se realizasse, e que deveriam ampliar o tempo ou recorrer ao uso de outros recursos para facilitar a aprendizagem, não lhes compete alterar o que foi previsto pelo professor. Assim, revela-se que os tutores não gozam de autonomia suficiente para introduzir mudanças no processo de ensino-aprendizagem (Regina; Maria).

A descontinuidade da formação em educação e-learning surge em quase todos os discursos como um problema, já apontado por Amante (2011), que os deixa desatualizados frente aos avanços das tecnologias digitais passíveis de utilização na educação, principalmente considerando que alguns docentes não receberam formação alguma antes de iniciar suas atividades em e-learning na UAb-Pt. 
De todo modo, para realizar esse trabalho, é necessário adquirir novos conhecimentos. Assim, as vozes são consoantes em afirmar que o novo modelo pedagógico é desafiante também "[...] porque implica aprendizagens novas, [...] uma nova atitude, [...] descobrir aspetos positivos que este tipo de modelo de ensino tem, portanto, acaba por nos envolver e, portanto, acaba por ser um desafio e nós aprendemos bastante e investimos" (João).

Assim, a retomada da formação contínua do tipo imersão é uma necessidade apontada - com recusa a práticas presenciais-, para a atualização docente em tecnologia educacional multimídia, aliadas à introdução de mecanismos que permitam a troca permanente de experiências e reflexões entre os docentes, tal como sugere Schlemmer (2010).

Considera-se também a necessidade de melhorar o acesso aos equipamentos para que os docentes possam disponibilizar novas ferramentas aos estudantes, assim como melhorar a gestão pedagógica e científica dos cursos, alinhando-as com as potencialidades do modelo, evitando-se, como afirma Miguel, uma gestão "muito burocrática, pouco reflexiva [...] limitada (que) não transforma ou leva você a considerar o seu trabalho cada vez mais rotineiro [...] (e), você perde...deixa de investir e como tal, perde qualidade da experiência [...], perde o interesse, perde a alma, não é?" (Miguel).

Sugestões surgem nos discurso para a introdução de outros recursos de Web 2.0, que poderão aproximar mais ao estudante (videoconferências, chats, etc), uma vez que o modelo assíncrono ainda o deixa em certo isolamento (Luiza). Portanto reconhece-se a necessidade de flexibilizar mais o modelo, no sentido de incorporar novas tecnologias, transcorrida a fase de sua consolidação.

A inserção dos tutores na equipe de trabalho, como parte do quadro profissional da UAb-Pt, respeitando a sua qualificação, é uma demanda presente nos discursos, afirmando-se que esta não foi escutada pela instituição, permanecendo estes com vínculos precários, a despeito de sua relevância na linha de frente do processo educativo online da UAb-Pt.

A voz do ex-gestor é enfática ao afirmar que a retomada e fortalecimento da investigação permanente e crítica sobre a experiência da UAb-Pt é aspecto crucial para a atualização e desenvolvimento pleno do modelo, podendo gerar subsídios para a incorporação de inovações e para identificar elementos que podem comprometer a qualidade da educação, tais como a insatisfação dos docentes e tutores, a escassez de equipamentos, a desatualização dos recursos multimídia utilizados, dentre outros.

\section{7| CONSIDERAÇÕES FINAIS}

O modelo pedagógico da UAb-Pt possui uma estrutura de concepção e organização que o tornam com potencial para realizar um processo educativo em e-learning dinâmico e bem sucedido, de uma perspectiva inovadora e emancipadora. O e-learning se mostra nas diferentes vozes como um modelo pedagógico adequado e necessário à inclusão social e intercultural, pois permite ampliar o acesso de grande número de estudantes ao ensino superior e à aprendizagem ao longo da vida, segundo seus interesses, sua disponibilidade de tempo e nos lugares mais distantes do mundo. Além disso, a abordagem sócio-construtivista contribui para o crescimento pessoal, com potencial para o desenvolvimento de novas competências, novas relações e a formação de sujeitos críticos e intelectualmente autônomos.

Contudo, embora se mostre bem estruturada, flexível quanto ao tempo e espaço, e sujeita à permanente atualização, a prática pedagógica da UAb-Pt se encontra em um momento crítico, exigindo maior abertura na aplicação do modelo para a adequação de métodos e técnicas por aqueles que estão na linha de frente, interagindo diretamente com os estudantes, facilitando o apren- 
dizado. Exige também que a formação docente e a investigação sejam continuadas, no sentido de assegurar a permanente reflexão crítica sobre as práticas.

Entretanto, há que se ressaltar que a experiência de e-learning da UAb-Pt tem se mostrado muito rica e mesmo bem sucedida, com resultados positivos na formação profissional, tanto no nível do primeiro como no segundo e terceiro ciclo. Essa avaliação positiva convive com pontos críticos na experiência, que dificultam o pleno desenvolvimento das potencialidades do modelo, os quais estão relacionados, no plano macrossocial, a questões políticas e econômicas do país no contexto europeu de ajustes fiscais, que levaram ao aumento do número de estudantes sem o correspondente aumento do número de docentes, e à acentuação da precarização das relações de trabalho. No plano micro social ou institucional, destaca-se a necessidade de lideranças proativas no sentido de buscar e adequar recursos e manter as atividades de formação e investigação contínuas, com a reflexão crítica e atualização constante das práticas. Destaca-se também a importância da valorização do tutor como profissional que está na linha de frente do processo, ao lado do professor, cujas relações horizontalizadas podem tornar o processo de ensino-aprendizagem da UAb-Pt mais rico, dinâmico e criativo.

De todo modo, o modelo pedagógico da UAb-Pt é uma excelente referência para a organização da Educação a Distância e-learning, por oferecer pistas, reflexões e desafios para a prática de ensino-aprendizagem em e-learning e para o desenvolvimento de competências de aprendizagem, tanto com seus avanços como com seus limites na sociedade aberta, em rede e tecnológica contemporânea. 


\section{REFERÊNCIAS}

AIRES, L. Do silêncio à polifonia: contributos da teoria sociocultural para a educação online. Discursos - Série: Perspectivas em Educação, Lisboa: Universidade Aberta, p. 23-35, dez. 2003. Disponível em: <https://www. researchgate.net/publication/260018721_Do_Silencio_a_Polifonia_Contributos_da_Teoria_Sociocultural_ para_a_Educacao_Online>. Acesso em: 29 jun. 2016.

E-learning, educação online e educação aberta: contributos para uma reflexão teórica. RIED - Revista Iberoamericana de Educación a Distancia, v. 19, n. 1, p. 253-269, 2016. Disponível em: <http://dx.doi. org/10.5944/ried.19.1.14356>. Acesso em: 29 jun. 2016.

ALVES, L.; NOVA, C. Educação a distância: limites e possibilidades. In: _____._. Educação a distância: uma nova concepção de aprendizado e interatividade. São Paulo: Futura, 2003. p.1-23.

AMANTE, L. Formação de professores a distância: a experiência da Universidade Aberta de Portugal. Revista Percursos, Florianópolis, v. 12, n. 1, p. 9-26, jan./jun. 2011. Disponível em: <http://www.periodicos.udesc.br/ index.php/percursos/article/view/2292/1737>. Acesso em: 10 ago. 2016.

AMANTE, L. et al. Novos contextos de aprendizagem e educação online. Revista Portuguesa de Pedagogia, ano 42-3, p. 99-119, 2008. Disponível em: <https://www. researchgate.net/publication/259715375>. Acesso em: 10 ago. 2016.

ARETIO, L. G. Los inicios históricos de una compleja universidad pública a distancia: la UNED de España. RIED - Revista Iberoamericana de Educación a Distancia, v. 19, n. 1, p. 9-21, 2016. Disponível em: <http://dx.doi. org/10.5944/ried.19.1.15057>. Acesso em: 15 jun. 2016.

AVENDAÑO, W. R. Un modelo pedagógico para la educación ambiental desde la perspectiva de la modificabilidad estructural cognitiva. Luna Azul, n. 36, p. 110-133, 2013. Disponível em: <http://www.scielo.org.co/pdf/luaz/ n36/n36a09.pdf>. Acesso em: 15 jun. 2016.

BAKHTIN, M. Discourse in the novel. In: The dialogic imagination. Austin, Texas: University of Texas Press, 1981. p. 259-300.

BECHARA, J. J. B.; HAGUENAUER, C. J. Estilos de aprendizagem e interfaces adaptativas em ambiente virtuais na plataforma Moolde. In: HAGUENAUER, C. J.; FILHO, F. C. (Org.). Os desafios da educação online e a contribuição do Laboratório de Pesquisa em Tecnologias da Informação e Comunicação LATEC/UFRJ. Curitiba: CRV, 2012a. p. 66-72.
- Revisitando a fundamentação pedagógica dos modelos educacionais a distância mediados pela tecnologia. In: HAGUENAUER, C. J.; FILHO, F. C. (Org.). Os desafios da educação online e a contribuição do Laboratório de Pesquisa em Tecnologias da Informação e Comunicação LATEC/UFRJ. Curitiba: CRV, 2012b. p. 53-63.

CARMO, H. D. de A. Modelos ibéricos de ensino superior a distância no contexto mundial. 1994. 571 f. Tese (Doutorado em Ciências de Educação) - Universidade Aberta, Lisboa, 1994. Disponível em: <http://repositorioaberto.uab.pt/bitstream/10400.2/2491/4/1994-versao\%20digital\%20da\%20tese $\% 20$ de $\% 20$ doutoramento.pdf>. Acesso em: 15 dez. 2015.

CASTELLS, M. A sociedade em rede. Lisboa: Fundação Calouste Gulbenkian, 2002.

CASTRO, R. I. V. G.; MATTEI, G. Tutoria em EaD on-line: aspectos da comunicação que favorecem a interação sócio-afetiva em comunidades de aprendizagem. Revista Brasileira de Aprendizagem Aberta e a Distância, v. 7, p. 1-23, 2008. Disponível em: <http://www.abed.org.br/ revistacientifica/Revista_PDF_Doc/2008/ARTIGO_22_ RBAAD_2008_PESQUISA.pdf>.Acessoem:17set. 2016.

CHAGURI, J. P. As vozes de uma política de ensino de língua estrangeira moderna na educação básica no Estado do Paraná. Acta Scientiarum Education, Maringá, v. 32, n. 2, p. 225-236, 2010. Disponível em: <http:// periodicos.uem.br/ojs/index.php/ActaSciEduc/article/ view/11219>. Acesso em: 07 dez. 2015.

DIAS, S. S. Dialógica e interatividade em educação online. Revista Digital Simonsen, Rio de Janeiro, n. 1, p. 19-32, dez. 2014. Disponível em: <www.simonsen.br/ revistasimonsen>. Acesso em: 17 ago. 2016.

FERNANDES, G. F.; FERREIRA, C. A. Desenho de conteúdos elearning: quais teorias de aprendizagem podemos encontrar? RIED - Revista Iberoamericana de Educación a Distancia, v. 15, n. 1, p. 79-102, 2012. Disponível em: <http://revistas.uned.es/index.php/ried/ article/view/778/688>. Acesso em: 13 maio 2016.

FILATRO, A. As teorias pedagógicas fundamentais em EAD. In: LITTO, F. M.; FORMIGA, M. (Org.). Educação a distância: o estado da arte. São Paulo: Pearson Education do Brasil, 2009. p. 96-104.

FLORES, N. M.; SILVEIRA, A. C. M. A produção de identidades de ciência na Revista Galileu: efeitos de sentido de monofonia ou polifonia? In: SIMPÓSIO NACIONAL DISCURSO, IDENTIDADE E SOCIEDADE, 3., 2012, Campinas. Anais... Campinas: Unicamp, 2012. Disponível em: <http://www.iel.unicamp.br/sidis/anais/pdf/FLORES_ NATALIA_MARTINS.pdf>. Acesso em: 18 jun. 2016. 
FONTES, A. R.; SCARELI, G.; VERSUTI, A. C. Reflexões sobre o caráter inclusivo da educação a distância: o papel do mediador pedagógico. In: LINHARES, R. N.; FERREIRA, S. L. (Org.). Educação a distância e as tecnologias da inteligência: novos percursos de formação e aprendizagem. Maceió: Edufal, 2011. p. 115-142.

FREITAS, L. K. M. R. Heterogeneidade e polifonia d(n) o discurso acadêmico: as vozes que habitam o dizer científico. Revista Linguasagem, ed. 16, 2011. Disponível em: <http://www.letras.ufscar.br/linguasagem/ edicao16/art_006.pdf>. Acesso em: 13 jul. 2016.

GADOTTI, M.; ROMÃO, J. E. Prefácio. In: GOMEZ, M. V. Educação em rede: uma visão emancipadora. São Paulo: Cortez , 2004. p.13-19.

GARCÍA, A. M. F.; ESTEBAN, A. P. Educar haciendo uso de las nuevas tecnologías y medios digitales: algunas pautas básicas. RED - Revista de Educación a Distancia, n. IX, nov. 2009. Disponível em: <http://revistas.um.es/red/article/view/87811>. Acesso em: 17 ago. 2016.

GIDDENS, A. O mundo na era da globalização. Barcarena: Editorial Presença, 2002.

GOMEZ, M. V. Educação em rede: uma visão emancipadora. São Paulo: Cortez , 2004.

HUNG, D.; LOOI, C.-K.; KOH, T.-S. Situated cognition and communities of practice: first-person "lived experiences" vs. third-person perspectives. Educational Technology \& Society, v. 7, n. 4, p. 193-200, 2004. Disponível em: <http://www.ifets.info/journals/7_4/18.pdf>. Acesso em: 12 maio 2016.

JONASSEN, D. O uso das novas tecnologias na educação a distância e a aprendizagem construtivista. Em Aberto, Brasília, ano 16, n. 70, p. 70-88, abr./jun. 1996. Disponível em: <http://emaberto.inep.gov.br/index.php/ emaberto/article/viewFile/2082/2051>. Acesso em: 12 maio 2016.

KOP, R.; HILL, A. Connectivism: learning theory of the future or vestige of the past? The International Review of Research in Open and Distance Learning, v. 9, n. 3, 2008. Disponível em: <http://www.irrodl.org/index.php/ irrodl/article /view/523/1103>. Acesso em: 15 ago. 2016.

MANSOS, L. M. S. A influência do e-learning no capital humano. Estudo de caso para o universo dos estudantes dos PALOP na Universidade Aberta. Tese de Doutoramento em Gestão . Universidade Aberta, Libsoa, 2014.
MASON, R. Models and methodologies in distance education. Discursos - Série: Perspectivas em Educação, Lisboa: Universidade Aberta, p. 91-101, dez. 2003. Disponível em: <https://repositorioaberto.uab.pt/bitstream/10400.2/151/1/Revista-Discursos>. Acesso em: 12 maio 2016.

MORER. A. S. La educación a distancia como factor clave de innovación en los modelos pedagógicos. Discursos Série: Perspectivas em Educação, Lisboa: Universidade Aberta, p. 15-22, dez. 2003. Disponível em: <http://repositorioaberto.uab.pt/bitstream/10400.2/145/1/Revista-Discursos15-22.pdf>. Acesso em: 15 ago. 2016.

OLIVEIRA, C.; MÂNTUA, S. Qualidade e avaliação do ensino superior a distância em Portugal. In: FIDALGO, F. S. R. et al. (Org.). Educação a distância: meios, atores e processos. Belo Horizonte: CEAD-UFMG, 2013. p. 183-194.

PEREIRA, A. et al. Modelo pedagógico virtual da Universidade Aberta: para uma universidade do futuro. Lisboa: Universidade Aberta, 2007. Disponível em: <http:// repositorioaberto.uab.pt/bitstream/10400.2/1295/1/ Modelo\%20Pedagogico\%20Virtual.pdf>. Acesso em: 15 maio 2016.

RAMOS, N. Tecnologias digitais de informação e comunicação, interculturalidade e formação docente. EDA$P E C l$ - Revista de Educação a Distância, Práticas Educativas, Comunicacionais e Interculturais, Aracaju-UFS, v. 16, n. 1, p. 9-30, 2016. Disponível em: <http://www. seer.ufs.br/index.php/edapeci/article/view/5206/pdf_2 ISSN 2176-171X> Acesso em: 20 ago. 2016.

ROMAN, A. R. O conceito de polifonia em Bakhtin: o trajeto polifónico de uma metáfora. Letras, Curitiba: Editora da UFPR, n. 41-42, p. 207-220, 1992-93. Disponível em: <http://revistas.ufpr.br/letras/article/view/19126/12426>. Acesso em: 15 ago. 2016.

ROMÃO, E. S.; MATTOS, M. O. O. Autonomia e dialogia na educação a distância: aproximações críticas. In: LINHARES, R. N.; FERREIRA, S. L. (Org.). Educação a distância e as tecnologias da inteligência: novos percursos de formação e aprendizagem. Maceió: Edufal, 2011. p. 59-82.

SANTOS, M. L. R.; RAMOS, N. Aprendizagem móvel e interculturalidade: produção científica em cursos de pós-graduação da Universidade Aberta de Lisboa. EDAPECl - Revista de Educação a Distância, Práticas Educativas, Comunicacionais e Interculturais, Aracaju-UFS, v. 16, n. 1, p. 95-114, 2016. Disponível em: <http://www. seer.ufs.br/index.php/edapeci/article/view/5035/pdf_1>. Acesso em: 15 ago. 2016. 
SCHLEMMER, E. Formação de professores na modalidade on-line: experiências e reflexões sobre a criação de espaços de convivência digitais virtuais. Em Aberto, Brasília, v. 23, n. 84, p. 99-122, nov. 2010. Disponível em: <http://emaberto.inep.gov.br/index.php/emaberto/ article/view/2264/2231>. Acesso em: 15 jul. 2016.

SILVA, M. Sala de aula interativa. 3. ed. Rio de Janeiro: Quarter, 2002.

SOBRAL, N., RAMOS, M. N. P. Processo de Bolonha e Internacionalização do Ensino Superior. Revista Tempos e Espaços em Educação. 2012. (8): 107-115.

SOBRAL, N.; RAMOS, M. N. P. Integração das tecnologias da informação e comunicação na formação docente em Portugal (2005-2010). Revista Praxis Educacional, v. 9, n. 14, p. 103-122, 2013.

SOBRAL, N.; RAMOS, M. N. P. Pedagogia Online: abordagem intercultural sobre os discursos de integração das tecnologias da informação e comunicação à educação em Portugal (2005-2010). In: OLIVEIRA, I. A. (Org.). Conceitos e percursos da Educação sob diferentes olhares. Maceió, EDUFAL, 2015. p. 147-188.
SOBRINHO, E. C. M.; HAGUENAUER, C. J. Ambientes virtuais, hipermídia, multimídia, games, realidade virtual, virtual heritage: definições, conceitos, similaridades e singularidades. In: HAGUENAUER, C. J.; FILHO, F. C. Ambientes virtuais de aprendizagem: dos sistemas de gerenciamento aos games e à realidade virtual. Curitiba: CVR, 2012. p. 29-43.

TELES, L. A aprendizagem por e-learning. In: LITTO, F. M.; FORMIGA, M. (Org.). Educação a distância: o estado da arte. São Paulo: Pearson Education do Brasil, 2009. p. $72-80$.

UNESCO. Policy guidelines for mobile learning. The United Nations Educational, Scientific and Cultural Organization 7. Fontenoy, 75352 Paris 07 SP, France. 2013. Disponível em http://www.unesco.org/new/en/ unesco/themes/icts $/ \mathrm{m} 4 \mathrm{ed} / \mathrm{mobile-learning-resources/}$ unescomobilelearningseries $/$ ?utm_source $=$ twitterfeed\&utm_medium=twitter

VELASQUEZ, F. R.; LOPEZ, J. M. B. Autoconcepto estudiantil y modalidades de enseñanza a distancia (B-Learning y E-learning). Paradígma, v. 30, n. 2, p. 99112, 2009. Disponível em: <http://www.scielo.org.ve/ pdf/pdg/v30n2/art07.pdf>. Acesso em: 13 maio 2016. 